Original Article

\title{
BIOFILM FORMATION OF METHICILLIN AND VANCOMYCIN RESISTANT STAPHYLOCOCCUS SPECIES ISOLATED FROM CELLULAR PHONES
}

\section{SWATI PATTNAIKa, SHATABDI MISHRAa, SWATI MOHAPATRA ${ }^{\text {* }}$, CHANDI CHARAN RATHc, SUDIPTA MAITYa, DEVIPRASAD SAMANTARAYa ${ }^{*}$}

aDepartment of Microbiology, OUAT, Bhubaneswar-3, Odisha, India, bepartment of Biotechnology, Indian Institute of Technology, Roorkee, India, cDepartment of Botany, CBSH, OUAT, Bhubaneswar-3, Odisha, India

Email: dpsamantaray@yahoo.com,swatismile016@gmail.com

Received: 11 Oct 2017 Revised and Accepted: 13 Feb 2018

\section{ABSTRACT}

Objective: The goal of the study was to explore the occurrence of methicillin and vancomycin-resistant Staphylococcus species from cellular phones and preventive measures to avoid contamination.

Methods: The issues addressed in this investigation are i) Isolation of bacteria from 70 cellular phones through swab culture method ii) Characterization of the isolates by standard biochemical test iii) Antibiogram pattern study of the isolates iv) Molecular identification of the selected isolate through 16s rDNA sequencing v) Virulence study through biofilm assay vi) Susceptibility of the isolates against commonly used disinfectants and essential oils through disc diffusion.

Results: All 70 different cellular phone used in this study harbored 120 isolates of bacteria. Of which, we recorded high incidence of Gram-positive cocci (51.6\%) and 22 isolates were identified as Staphylococcus species. Three isolates (52N6, 53N9 and 53N6) were resistant to both methicillin and vancomycin, in addition, showed resistance against several other antibiotics. The strain 53N6 that exhibited multidrug resistance was further identified as Staphylococcus sp. strain CPC53N6 through 16s rDNA sequencing with NCBI accession no. KX858346. Virulence activity of the isolate was observed by its biofilm forming capacity as revealed from SEM imaging and the biofilms were composed of aggregated cocci and fibriform extracellular matrix. All the Staphylococcus isolates, including CPC53N6, were sensitive to disinfectants like dettol and cinnamon (Cinnamon zeylanicum) oil indicating their use as preventive measures.

Conclusion: Thus, the methicillin and vancomycin-resistant Staphylococcus species of cellular phones can be decontaminated through cinnamon oil to minimize further transmission.

Keywords: Staphylococcus, Cellular, Biofilm, Antibiogram, Cinnamon oil

(C) 2018 The Authors. Published by Innovare Academic Sciences Pvt Ltd. This is an open access article under the CC BY license (http://creativecommons.org/licenses/by/4.0/) DOI: http://dx.doi.org/10.22159/ijpps.2018v10i3.23051

\section{INTRODUCTION}

The cellular phone user in India by $2009-10$ reached to 584.32 million for communication. These cellular phones are hand-held and constant handling by different users exposes it to a wide array of microbes as well as a potential carrier for their transmission [1]. Staphylococci are recognized nosocomial pathogens of cellular phone causing skin, intra-abdominal and pelvic site wound infections [2, 3]. Moreover, biofilm formation by Staphylococci species has been depicted as a predominant virulence factor. As a matter of fact, a well-defined disinfection practice should be employed for removal of these multi-drug resistant bacteria [4]. Although the intensive research was focused towards the presence of Enterobacter aerogenes, Pseudomonas aeruginosa, Micrococcus luteus, Bacillus subtilis, Staphylococcus epidermidis [5]. However, very few findings are available regarding methicillin-resistant Staphylococcus aureus (MRSA) [6, 7]. Thus, the objective of the study was to explore the occurrence of methicillin and vancomycinresistant Staphylococcus species from cellular phones and preventive measures to avoid contamination.

\section{MATERIALS AND METHODS}

\section{Sample collection and bacteriological analysis}

The cellular phones of 70 different users including staff and students of the department of microbiology, OUAT, Bhubaneswar, Odisha were selected for this study. The isolation of bacteria was carried out by standard swab culture method using nutrient agar (NA). Individual bacterial isolates were sub-cultured on NA medium to obtain pure culture and preserved at $4{ }^{\circ} \mathrm{C}$ for further characterization. Based on Gram variability, the Gram-positive cocci were selected for different characterizations such as blood haemolysis, indole, catalase, oxidase, coagulase, mannitol and antibiotic sensitivity. Further, the isolates were identified up to generic level from morpho-physiological characterization using Bergey's manual of determinative bacteriology [8].

\section{Chemicals and reagents}

Most of the culture media used for the isolation and characterization of bacteria were prepared as per the manufacturer's instruction by using double distilled water. All the culture media and chemicals were procured from Hi-media laboratories private limited, Mumbai.

\section{Antibiogram profile of Staphylococcus species}

The Staphylococcus species were subjected to antibiotic sensitivity assay against methicillin (10 mcg), vancomycin (5 mcg), linozolid (30 mcg), erythromycin (15 mcg), tetracycline $(30 \mathrm{mcg})$, penicillin $(10 \mathrm{mcg})$, ceftriazone-tazobactumn $(30-10 \mathrm{mcg})$, amoxyclav $(30 \mathrm{mcg})$, cefixime (5 $\mathrm{mcg}$ ), imipenem (10 mcg), co-trimazole (25 mcg), clindamycin (2 mcg) and rifampicin (30 $\mathrm{mcg}$ ) by disc diffusion method [9].

\section{Molecular characterization of Staphylococcus species}

An attempt was made to characterize the methicillin and vancomycin-resistant Staphylococcus species through 16s rDNA analysis [10]. Briefly, the extracted DNA was quantified by using nano-drop and stored at $-20^{\circ} \mathrm{C}$ in TE buffer till further use. The $16 \mathrm{~S}$ rDNA sequencing was done through Eurofins Labs Ltd., Ahmedabad, India, using forward and reverse 27F (AGA GTT TGA TCC TGG CTC AG) and 1492R (TAC GGT TAC CTT GTT ACG ACT T) primers BDT v3.1 cycle sequencing kit on $\mathrm{ABI} 3730 \mathrm{xl}$ genetic analyzer. The consensus sequence of $16 \mathrm{~S}$ rDNA was analyzed by Bio-Edit software 
v7.0.5.3 and submitted to NCBI (http://blast.ncbi.nlm.nih.gov/ blast.cgi) for generation of accession number. The 16S rDNA consensus sequence of the isolate was subjected to multiple sequence analysis using ClustalW v1.6. The phylogenetic tree was constructed using a neighbour-joining method by MEGA v6.0 (molecular evolutionary genetics analysis) software [11]. The resultant phylogenetic tree topologies were evaluated by bootstrap analysis of neighbour-joining data sets based on 1000 re-samplings.

\section{Biofilm production by Staphylococcus species}

The qualitative assay of biofilm formation by Staphylococcus species was conducted using tube, congo red plate method [12] and followed by scanning electron microscopic (SEM) analysis [13]. Briefly, the fresh culture of Staphylococcus species was inoculated to brain heart infusion (BHI) broth containing $0.5 \%$ sucrose and incubated at $37^{\circ} \mathrm{C}$ for $24-48 \mathrm{~h}$. The specimens were immersed in Karnovsky's solution for $30 \mathrm{~min}$. The fixed specimens were rehydrated using different grade ethanol and transferred to butyl alcohol, freeze-dried and coated with gold for SEM observation at 15000X magnification (FE-SEM Quanta $200 \mathrm{FEG}$ ).

\section{Antibacterial activity of disinfectants and essential oils against Staphylococcus species}

The antibacterial activity of some common disinfectants like dettol, suthol, hand sanitizer and extracted essential oils of cinnamon (Cinnamon zeylanicum), nutmeg (Myristica fragrance) and neem (Azadirachta indica) oil was evaluated by disc diffusion method [9]. Briefly, the day old cultures of bacterial isolates were uniformly spread on muller-hinton (MH) agar plate using a sterile cotton swab. Then, sterile discs containing $20 \mu \mathrm{l}$ of each disinfectant or essential oil was placed separately in the MH agar plate and incubated at 37 ${ }^{\circ} \mathrm{C}$ for $24 \mathrm{~h}$. After the incubation period, plates were observed for zones of inhibition around the discs indicating the positive antibacterial activity of the agents. Further, SEM observation (10000X magnifications) was also carried out to observe the effect of disinfectant and essential oil against Staphylococcus species.

\section{RESULTS AND DISCUSSION}

\section{Bacteriological analysis of cellular phones}

Cellular phones provide an ideal environment for colonization of various non-pathogenic and pathogenic microbes, as it generates heat and has numerous slits for the accumulation of dust particles and moisture [14]. In this investigation, we observed a high degree of bacterial colonization including Staphylococcus species on cellular phones. In toto 120 bacteria were isolated from 70 different cellular phone users including staffs and students of the department of microbiology, OUAT, Bhubaneswar, Odisha. Results of the research work depicted a high degree $(100 \%)$ of bacterial association with cellular phones including $51.60 \%$ were Gram-positive cocci, $40.80 \%$ Gram positive rod and 7.50\% Gram negative rod respectively. Out of 62 Gram positive cocci (fig. 1a), 25 were $\beta$-hemolytic (fig. 1b); among them, $88 \%$ were coagulase positive. The $\beta$-hemolytic and coagulase positive bacteria belongs to the genera Staphylococcus as confirmed from their morpho-physiological characterizations. In contrast to our results, an association of different bacteria such as Staphylococcus aureus, Enterococcus faecalis, Pseudomonas aeruginosa, Escherichia coli, Klebsiella sp., Streptococcus sp., Bacillus cereus, Proteus mirabilis, Salmonella sp., Shigella sp. with cellular phones were also reported earlier [15, 14]. In addition, healthcare workers hand and cellular phones were also contaminated with various types of bacteria including nosocomial pathogens [6]. Moreover, colonization of these bacteria on cellular phones could be due to transmission of bacteria from hand, mouth, ear and skin during handling and aerosols.
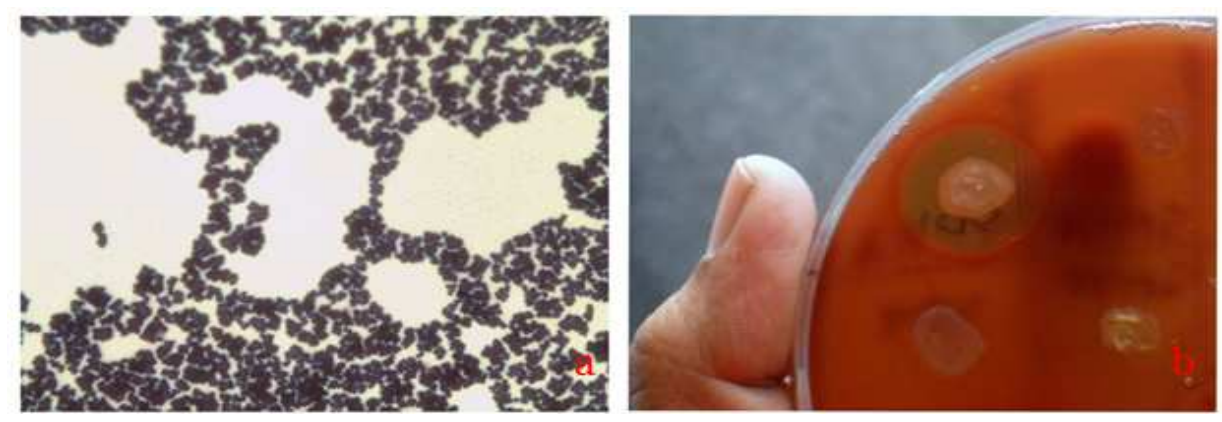

Fig. 1: a. Micrograph of Staphylococcus sp. strain CPC53N6, and b. $\beta$-hemolytic Staphylococcus sp. strain CPC53N6

\section{Antibiogram profile of Staphylococcus species}

The antibiogram pattern of Staphylococcus species indicated that $10 \%$ of the bacterial isolates were resistant to methicillin. Among them, Staphylococcus sp. 52N6, Staphylococcus sp. 53N9 and Staphylococcus sp. 53N6 were resistant to both methicillin and vancomycin. Notably, Staphylococcus sp. 53N6 was resistant to various third generation antibiotics such as amoxiclav, clindamycin, vancomycin, erythromycin, methicillin, linozolid, penicillin used in the study. This is the first report demonstrating the association of multi-drug resistant Staphylococcus sp. 53N6 with the cellular phones. Similarly, colonization of $37.7 \%, 3.84 \%$ and $2.4 \%$ methicillin-resistant Staphylococcus species with cellular phones of different users was also reported before $[6,16,17]$.

\section{Molecular identification of the Staphylococcus species}

The 16s rDNA sequence of Staphylococcus sp. 53N6 was subjected for BLAST analysis and the best twenty five hits were selected on the basis of highest percentage of similarity and lowest expected value. Further, the phylogenetic tree was constructed using these twentyfive homologous sequences and sequence of Staphylococcus sp. 53N6 (fig. 2). The in silico analysis revealed that the Staphylococcus sp. 53N6 99\% similar with Staphylococcus arlettae VIT-RJ1
(KJ716448.1). The identified bacterium is Staphylococcus sp. strain CPC53N6 with accession no. KX858346.

\section{Biofilm formation by Staphylococcus species}

Formation of black colored colonies on congo red agar plate (fig. 3a) by Staphylococcus sp. strain CPC53N6 indicating biofilm formation as compared to control that exhibiting red colonies with dry crystalline morphology. Similarly, biofilm formation by the Staphylococcus sp. strain CPC53N6 was observed using tube method (fig. $3 \mathrm{~b}$ ). In addition, biofilm formation by the bacterial isolate was also confirmed from SEM studies, which indicate that the biofilms were composed of aggregated cocci and fibriform extracellular matrix-like structures (fig. 3d) as compared to control (fig. 3c). The virulence factor of Staphylococcus sp. strain CPC53N6 was confirmed from biofilm formation. This enhances their resistance to antibiotics and also contributes in genetic exchange. Although earlier studies reported that $[2,18]$ biofilm production is more commonly associated with clinical isolates than non-clinical one. Thus, an association of such type of potential opportunistic pathogens on cellular phones has a significant concern. Increased attention should be given to reduce contamination of Staphylococcal strains from cellular phones using good hand hygiene practices. 


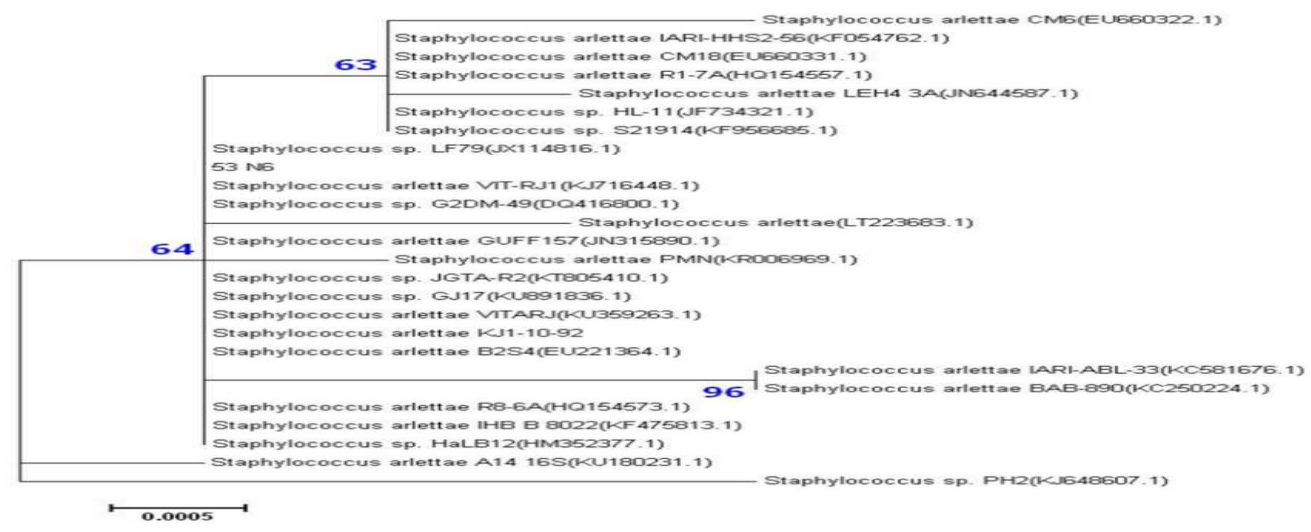

Fig. 2: Phylogenetic tree illustrating divergence between Staphylococcus sp. strain CPC53N6 with 16s rDNA homologous sequence resulted from a BLAST search
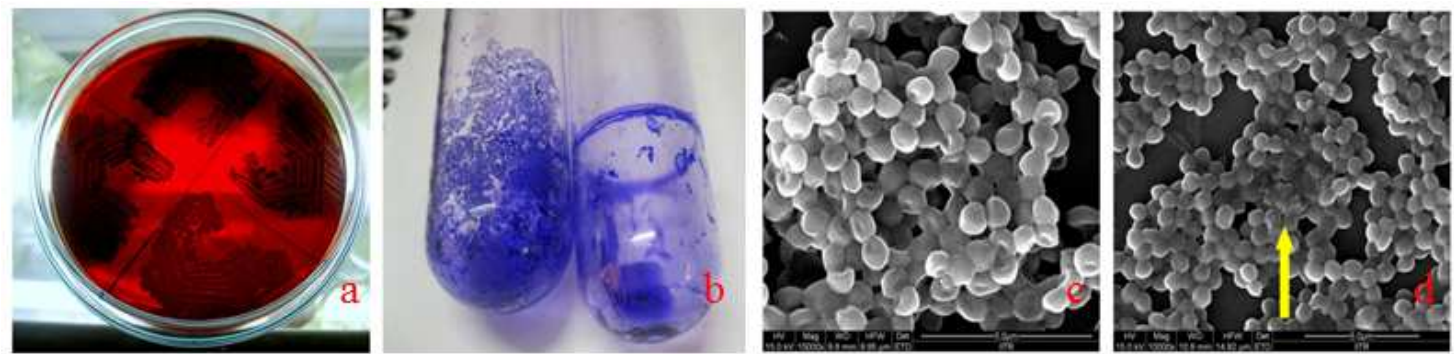

Fig. 3: Biofilm formation: a. congo red agar method, b. tube method, c. SEM image of Staphylococcus sp. strain CPC53N6, and d. SEM image depicting biofilm formation by Staphylococcus sp. strain CPC53N6

Antibacterial activity of disinfectant and essential oils against Staphylococcus species

This study revealed that all the $\beta$-haemolytic and coagulase positive Staphylococcus species were sensitive to dettol, cinnamon oil, suthol and nutmeg oil. However, most of the Staphylococcus species were moderately sensitive to neem oil and hand sanitizer (fig. 4 and $5 a$ ). Thus, the growth of Staphylococcus species was drastically reduced by dettol and cinnamon oil than other disinfectants used. Moreover, an SEM study was also confirmed regarding disruption of clustered cell arrangements and biofilm of Staphylococcus sp. strain CPC53N6 in presence of dettol (fig. 5d) and cinnamon oil (fig. 5c) as compared with control (fig. 5b) $[19,20]$. Presence of chloroxylenol and isopropyl alcohol in dettol [21] and cinnamaldehyde and eugenol in cinnamon oil $[22,23]$ inhibits the growth of bacterial isolates. Although different disinfection strategies including the application of isopropyl alcohol or ethyl alcohol [24, 17] and ultraviolet radiation [25] were reported earlier, but ultraviolet radiation [26] is not so effective against a wide array of microbes.

Thus, naturally available cinnamon oil can be an alternative of dettol, which not only kills the multi-drug resistant bacteria in vitro but also can secure highly sensitive cellular phone-like devices, as there is a growing demand for the search of natural antimicrobial compounds and disinfectants against costly harmful antimicrobial drugs or disinfectants.

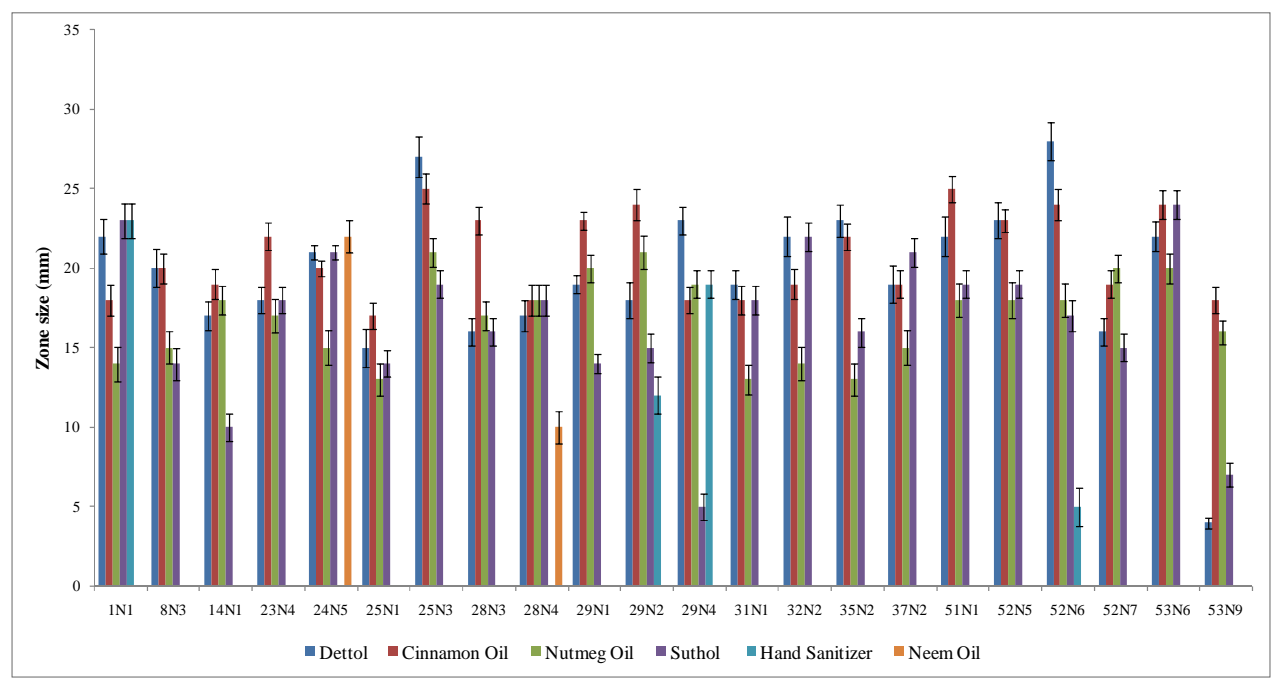

Fig. 4: Effect of disinfectants (Dettol [4.88 \pm 1.03$]$, Suthol [4.79 \pm 1.02$]$, Hand sanitizer [6.59 \pm 1.39$]$ ) and essential oil (Cinamon oil [4.92 \pm 1.04$]$, Nutmeg oil $[2.64 \pm 0.50]$, Neem oil $[5.58 \pm 1.07]$ on the growth of $\beta$-hemolytic, coagulase positive Staphylococcus species. Data were analyzed by one-way ANOVA $(p<0.05)$ and vertical bars represent standard error. Values in the square brackets indicate SD $\pm S E$ and $n=22$ for all cases 

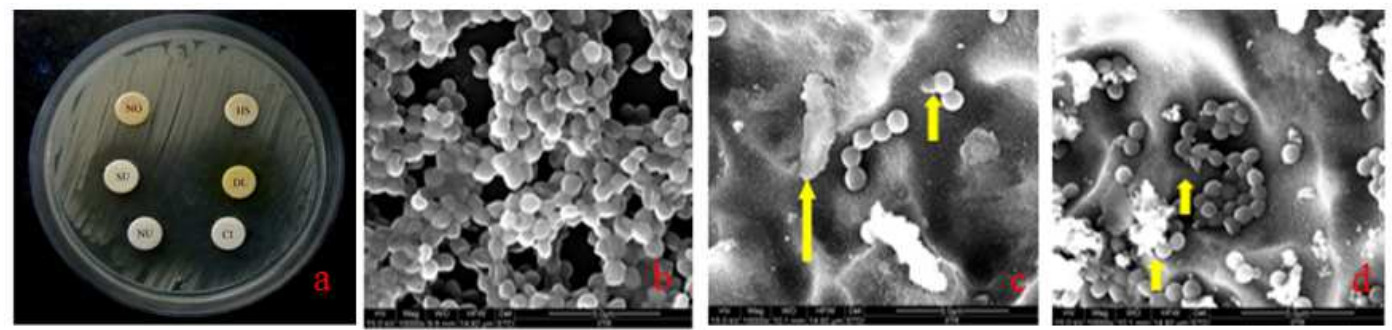

Fig. 5: a. Antibacterial activity of disinfectants and oils b. Staphylococcus sp. strain CPC53N6 without disinfectants and essential oils c. disruption of Staphylococcal cell cluster and biofilm with cinnamon oil and d. with dettol

\section{CONCLUSION}

In conclusion, cellular phones were highly contaminated by a wide array of bacteria including Staphylococcus species with a high degree of resistance to various third generation antibiotics. This suggests the potentiality of cellular phones as a carrier for transmission of infections with promising public health implications. As a matter of fact, we suggest an active preventive strategy like routine hand hygiene practices along with decontamination of cellular phones with volatile natural products cinnamon oil, which will reduce crossinfection without impeding the normal functions. On the other hand, cellular phone surface should be designed using cinnamon oil based antimicrobial additive materials to reduce transmission of microbes as well as spreading of various diseases in future.

\section{ACKNOWLEDGEMENT}

The authors are grateful to the head, Department Microbiology and Central Laboratory, OUAT, Bhubaneswar for providing facilities to undertake this research work.

\section{AUTHORS CONTRIBUTIONS}

The experimental studies including literature search were conducted by Swati Pattnaik, Shatabdi Mishra and Dr. Swati Mohapatra. The manuscript was prepared by Swati Pattnaik and Sudipto Maity. Planning of experiment and manuscript reviewing were carried out by Dr. Chandi Chran Rath and Dr. Deviprasad Samantaray.

\section{CONFLICT OF INTERESTS}

The authors have no conflict of interest to declare

\section{REFERENCES}

1. Kumar P, Aswathy ML. Identification of mobile phone associated pathogens. Kerala J Orthop 2014;27:69-72.

2. Garg S, Mohan B, Taneja N. Biofilm formation capability of enterococcal strains causing urinary tract infection vis-a-vis colonization and correlation with enterococcal surface protein gene. Ind J Med Microbiol 2017;35:48-52.

3. Mir BA, Srikanth. Prevalence and antimicrobial susceptibility of methicillin-resistant Staphylococcus aureus and coagulasenegative staphylococci in a tertiary care hospital. Asian J Pharm Clin Res 2013;6:231-4.

4. Pandey A, Asthana AK, Tiwari R, Kumar L, Das A, Madan M. Physician accessories: Doctor, what you carry is every patient's worry? Indian J Pathol Microbiol 2010;53:711-3.

5. Dave S, Shende K. Isolation and identification of microbes associated with mobile phones. J Env Sci Toxicol Food Technol 2015;1:71-3.

6. Ulger F. Are we aware how contaminated our mobile phones with nosocomial pathogens? Ann Clin Microbiol Antimicrob 2009;8:1-4.

7. Debnath T, Bhowmik S, Islam T, Chowdhury MMH. Presence of multidrug-resistant bacteria on mobile phones of health care workers accelerates the spread of nosocomial infection and regards as a threat to public health in Bangladesh. J Micro Ultrastruct 2017. Doi.org/10.1016/j.jmau.2017.09.004.

8. Holt JG, Krieg NR, Sneath PHA, Staley JT, Williams ST. Bergey's Manual of Determinative Bacteriology. 9th ed. USA: Williamson and Wilkins, Baltimore; 1994.

9. Bauer K, Kirby W, Sherris J, Truck M. Antibiotic susceptibility testing by a standardized single disc method. Am J Clin Path 1966;15:493-6.
10. Sambrook J, Russell DW. This protocol was adapted from commonly used techniques in molecular cloning, $3,3^{\text {rd }}, 8$. Cold Spring Harbor Laboratory Press. Cold Spring Harbor: NY USA; 2001.

11. Tamura K, Stecher G, Peterson D, Filipski A, Kumar S. MEGA6: molecular evolutionary genetics analysis version 6.0. Mol Biol Evol 2013;30:2725-9.

12. Mathur T, Singhal S, Khan S, Upadhyay DJ, Fatma T, Rattan A. Detection of biofilm formation among the clinical isolates of Staphylococci: an evaluation of three different screening methods. Ind J Med Microbiol 2006;24:25-9.

13. Asahi Y, Miura J, Tsuda T, Kuwabata S, Tsunashima K, Noiri Y, et al. Simple observation of Streptococcus mutans biofilm by scanning electron microscopy using ionic liquids. AMB Exp 2015;5:6.

14. Akinyemi KO, Atapu AD, Adetona OO, Cocer AO. The potential role of mobile phones in the spread of bacterial infections. J Inf Dev Count 2009;3:628-32.

15. Tagoe DN, Gyande VK, Ansah EO. Bacterial contamination of mobile phones: When your mobile phone could transmit more than just a call. Web Cent Microbiol 2011;2:21-5.

16. Pattnaik S, Dahiya A, Roy R. Spectrum of microorganisms isolated from mobile phones of general surgeons. Int J Sci Res Pub 2014;4:1-2.

17. Julian T, Singh A, Rousseau J, Weese JS. Methicillin-resistant Staphylococcal contamination of cellular phones of personnel in a veterinary teaching hospital. BMC Med Notes 2012;5:193-7.

18. Upadhyaya GP, Lingadevaru UB, Lingegowda RK. A comparative study among clinical and commensal isolates of Enterococcus faecalis for the presence of esp gene and biofilm production. J Inf Dev Count 2011;5:365-9.

19. Pratiwi SUT, Lagendijk EI, Hertiani T, Weert SD, Van Den Hondel CAMJJ. Antimicrobial effects of Indonesian medicinal plants extracts on planktonic and biofilm growth of Pseudomonas aeruginosa and Staphylococcus aureus. Int J Pharm Pharm Sci 2015; 7:183-91.

20. Kaushik S, Tomar RS, Shrivastava V, Shrivastav A, Jain SK. Antimicrobial efficacy of essential oils of selected plants and vaccine design against meca protein of methicillin-resistant Staphylococcus aureus. Asian J Pharm Clin Res 2014;7:52-6.

21. Lam PK, Chan CK, Tse ML, Lau FL. Dettol poisoning and the need for airway intervention. Hong Kong Med J 2012;18:270-5.

22. Matan N, Rimkeeree $\mathrm{H}$, Mawson AJ, Chompreeda $\mathrm{P}$, Haruthaithanasan V, Parker M. Antimicrobial activity of cinnamon and clove oils under modified atmosphere conditions. Int J Food Microbiol 2006;107:180-5.

23. Yahiaoui F, Benameur Q, Ben-Mahdi MH. Antibacterial activity of Mentha pulegium essential oil against avian isolated esbl producing bacteria and its synergistic potential with antibiotics. Int J Pharm Pharm Sci 2017;9:35-41.

24. Basol R, Beckel J, Gilsdorf-Gracie J, Hilleren-Listerud A, McCaffrey TD, Reischl S. Bacteria on shared mobile phones can lead to infections. Nurs Crit Care 2014;9:5-7.

25. Tekerekoglu MS, Duman Y, Serindag A, Cuglan SS, Kaysadu H, Tunc E, et al. Do mobile phones of patients, companions and visitors carry multidrug-resistant hospital pathogens? Am J Inf Cont 2011;39:379-81.

26. Otter JA, Yezli S, Perl TM, Barbut F, French GL. The role of 'notouch' automated room disinfection systems in infection prevention and control. J Hosp Inf 2013;83:1-13. 